\title{
Future Challenges in Southern Ocean Ecology Research
}

\begin{abstract}
José C. Xavier ${ }^{1,2 *}$, Angelika Brandt ${ }^{3}$, Yan Ropert-Coudert ${ }^{4}$, Renuka Badhe ${ }^{5}$, Julian Gutt ${ }^{6}$, Charlotte Havermans ${ }^{6,7}$, Christopher Jones ${ }^{8}$, Erli S. Costa ${ }^{9}$, Karin Lochte $^{6}$, Irene R. Schloss ${ }^{10,11,12}$, Mahlon C. Kennicutt II $^{13}$ and William J. Sutherland ${ }^{1,4}$

${ }^{1}$ British Antarctic Survey, Natural Environmental Research Council, Cambridge, UK, ${ }^{2}$ Departamento das Ciências da Vida, Faculdade de Ciências e Tecnologia, Marine and Environmental Sciences Centre, Universidade de Coimbra, Coimbra, Portugal, ${ }^{3}$ Zoological Museum, Centre of Natural History (CeNak), University of Hamburg, Hamburg, Germany, ${ }^{4}$ Centre $d$ ' Etudes Biologiques de Chizé, Centre National de la Recherche Scientifique UMR 7372, Villiers-en-Bois, France, ${ }^{5}$ European Polar Board, Den Haag, Netherlands, ${ }^{6}$ Alfred-Wegener-Institut, Helmholtz Zentrum für Polar-und Meeresforschung. Bremerhaven, Germany, ${ }^{7}$ Royal Belgian Institute of Natural Sciences, Brussels, Belgium, ${ }^{8}$ Southwest Fisheries Science Center, National Marine Fisheries Service, NOAA, La Jolla, CA, USA, ${ }^{9}$ Universidade do Estado do Rio Grande do Sul, Porto Alegre, RS, Brazil, ${ }^{10}$ Instituto Antártico Argentino, Balcarce, Argentina, ${ }^{11}$ Consejo Nacional de Investigaciones Científicas y Técnicas-CONICET, Buenos Aires, Argentina, ${ }^{12}$ Institut des Sciences de la mer de Rimouski, Rimouski, QC, Canada, ${ }^{13}$ Texas A \& M University, College Station, TX, USA, ${ }^{14}$ Conservation Science Group, Department of Zoology, University of Cambridge, Cambridge, UK
\end{abstract}

\section{OPEN ACCESS}

Edited by:

Michael Arthur St. John

Technical University of Denmark

Denmark

Reviewed by:

Philip Boyd,

Institute for Marine and Antarctic

Studies, Australia

David Michael Stoddart,

University of Tasmania, Australia

${ }^{*}$ Correspondence: Jose C. Xavier jccx@cantab.net

Specialty section: This article was submitted to Marine Ecosystem Ecology, a section of the journal Frontiers in Marine Science

Received: 20 November 2015 Accepted: 30 May 2016

Published: 14 June 2016

Citation: Xavier JC, Brandt A, Ropert-Coudert $Y$, Badhe R, Gutt J, Havermans C, Jones C, Costa ES, Lochte K, Schloss IR, Kennicutt MC II and Sutherland WJ (2016) Future Challenges in Southern

Ocean Ecology Research.

Front. Mar. Sci. 3:94

doi: 10.3389/fmars.2016.00094
The Southern Ocean is experiencing relentless change. The Antarctic and Southern Ocean community, represented by 75 scientists and policy-makers from 22 countries, recently met to formulate a collective vision on the priorities for Antarctic research for the next two decades and beyond. Here, we assess high-interest research areas related specifically to Southern Ocean life and ecology that, although not all retained as the 80 top priorities among the addressed scientific domains, are of considerable relevance to the biology and ecology of the Southern Ocean. As certain regions of the Southern Ocean ecosystems have witnessed abiotic and biotic changes in the last decades (e.g., warming, climate variability, changes in sea ice, and abundance of marine organisms), such an exercise was urgently needed. We concluded that basic biological information on the taxonomy of numerous organisms is still lacking in areas, such as the deep-ocean floor or the under-ice environments. Furthermore, there is a need for knowledge about the response and resilience of Antarctic marine ecosystems to change. The continuation of a long-term commitment and the development and use of innovative technology to adequately monitor the Southern Ocean ecosystems is required. Highlighting the most important Southern Ocean research topics allow the identification of the challenges and future requirements in technological development, and both research and funding strategies for the various stakeholders.

Keywords: Southern Ocean, future research, policy making, ecology, conservation

\section{INTRODUCTION}

The Southern Ocean represents $9.6 \%$ of the world's oceans and plays a key role in various global cycles and budgets. It is a major contributor to global oceanic primary production and biodiversity, exports nutrients to the world's ocean basins, and contributes to the global currents system transferring heat and $\mathrm{CO}_{2}$ from the atmosphere to the deep ocean and $\mathrm{O}_{2}$ in the opposite direction 
(Sarmiento et al., 2004; Turner et al., 2009). In the last 30 years, manifold regional change (e.g., in water temperature, in currents, stratification, shifts in oceanic front positions, increase in westerly winds, changes in sea-ice extent with dramatic consequences on wildlife, changes in Antarctic krill Euphausia superba abundance) took place in the Southern Ocean (Constable et al., 2014; Ropert-Coudert et al., 2014; Gutt et al., 2015). The "stability" of the Earth System (including natural background dynamics) is under threat, with the rate of change is accelerating (with core elements of climate change and biosphere integrity, that can drive the Earth System into a new state), suggesting that the current changes are only minor compared to the expected future trends (Rockstrom et al., 2009; Steffen et al., 2015). These trends include, inter alia, increased ocean warming, widespread decrease of sea ice, increase of aragonite undersaturation (acidification), and the interaction of these (and other) environmental factors that affect the Southern Ocean ecosystems (Gutt et al., 2015).

Although, our understanding of Southern Ocean biological processes (e.g., distribution, feeding ecology, reproduction; Figure 1) has improved considerably in recent years, the capacity of organisms (at population, community and/or species level) to

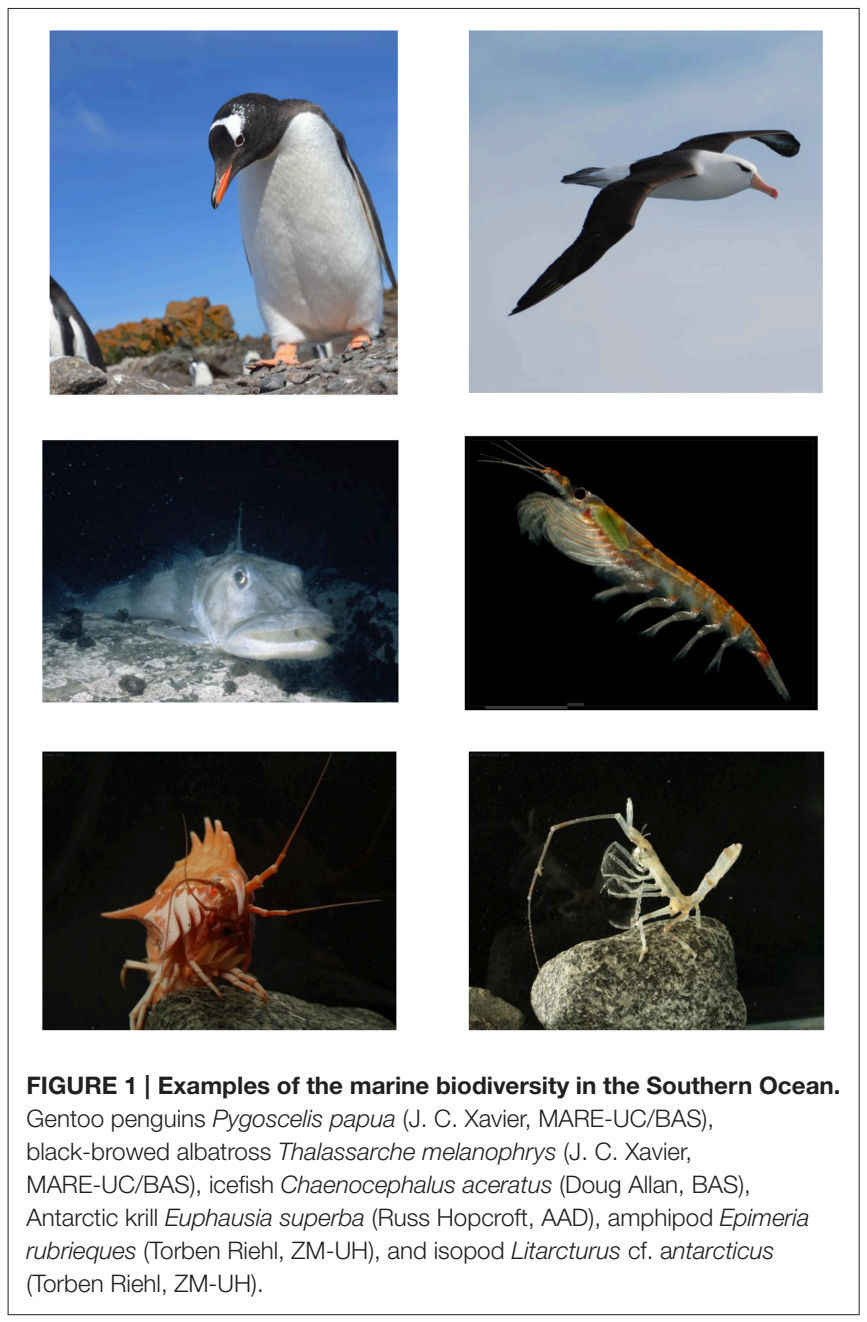

adapt to changes and the dynamics of biological cycles remain poorly understood. This knowledge, however, is essential for predicting biological responses to predicted physical changes (IPCC, 2013).

The First Scientific Committee on Antarctic Research (SCAR) Antarctic and Southern Ocean Horizon Scan, held in April 2014 in New Zealand, brought together 75 scientists and policymakers from 22 countries to suggest priorities for Antarctic Research in the coming two decades and beyond (Kennicutt et al., 2014, 2015). The Horizon Scan process (Sutherland et al., 2011), through which these priority issues were selected, has been described by Kennicutt et al. (2015). The authors identified several questions that fell widely into six research themes that might guide researchers to the full potential of Antarctic and Southern Ocean science (Kennicutt et al., 2014). Here, we focus on three topical clusters (Southern Ocean life and ecology, the marine biosphere and the physical environment, and biotic responses to change) that were identified as priority issues during the Horizon Scan and that relate specifically to Southern Ocean research. Our aim is to: (i) assess high-interest research areas that, although not retained at the end of the Scan [(Kennicutt et al., 2014, 2015) list the full top 80 questions], entered the exercise selection process for Southern Ocean biology and ecology, and (b) identify the challenges and requirements in technological developments, research strategies (e.g., monitoring and coordination), as well as links with stakeholders (e.g., policy makers, NGO's, industry) and the general public, specific to Antarctica and Southern Ocean biological research.

\section{RESEARCH RELEVANT TO SOUTHERN OCEAN LIFE AND ECOLOGY}

Besides a detailed compilation of research questions in the Data sheet 1 in Supplementary Material, we outline a number of issues related to the questions that were voted on the Southern Ocean life and ecology sessions herewith.

\section{Identification of Major Marine Ecosystem Processes in the Southern Ocean}

The continuous warming of parts of the Southern Ocean calls for an evaluation not only of the increasing temperature, but also of its impact on other physical and biological parameters. This is especially relevant to species endemic to the Southern Ocean (characterized by narrow environmental niches) that may display poor adaptability/acclimation/plasticity to rapid environmental changes. A key issue is identifying which species will be threatened by the changes because of their inherent physiological limitations. Increasing ocean acidification (i.e., decreasing seawater $\mathrm{pH}$ ) is expected to profoundly alter Southern Ocean ecosystems (Orr et al., 2005) but recent evidence suggests that some Antarctic species can cope with lowered pH (Suckling et al., 2014). Taxonomy remains a key approach for uncovering changes in faunal composition related to global change processes (Costello et al., 2013). 
Identifying the linkages between terrestrial and marine systems, particularly in inter-tidal and near-shore areas, where de-glaciation on land may have important effects on local marine ecosystems (Schloss et al., 2012; Gutt et al., 2015; Hernando et al., 2015), needs further research due to the predicted increase levels of ice melting, potential land-originated fresh water runoff, and potential increase in sea level (Golledge et al., 2015). In addition, although there is evidence of glacier impact on benthic communities at a local scale (Pasotti et al., 2015), it is essential to understand the factors that can explain the high spatial patchiness of Antarctic shelf-inhabiting benthos at local and regional scales.

Understanding the synergistic effects of multiple environmental stressors, including ocean acidification, sedimentation, and hypoxia, on benthic habitats will prove particularly challenging; however this is paramount to the understanding of whole ecosystem changes.

\section{Investigate the Food Web Structure and Functioning of the Southern Ocean}

Some basic biological information on primary production, zooplankton, nekton, and top predators from various regions of the Southern Ocean is still missing (Figures 2A,B; Griffiths et al., 2014). Benchmark knowledge has been gathered through the Census of Marine Life, and its flagship project, the 5 year Census of Antarctic Marine Life (CAML), which investigated, between others, the diversity, distribution, functions, and abundance of Southern Ocean marine organisms (Gutt et al., 2010; Kaiser et al., 2013), culminating into the Biogeographic Atlas of the Southern Ocean (Brandt et al., 2014b; De Broyer et al., 2014). However, knowledge gaps are still present concerning the biology, distribution, and diversity of most marine groups. As of today, very little information is available from the microbial realm (including viruses), particularly on their distribution in Southern Ocean ecosystems and their role in fueling and recycling organic matter in the different systems' compartments. Similarly, we know very little of the life cycle of many plankton and nekton species (of which large numbers remain unidentified) particularly under the sea ice, at the ice-ocean water interface and in the open ocean regions, or of the recruitment success any population dynamics of ecologically important taxa (e.g., cephalopods or myctophid midwater fish). In this context, from the food-chain perspective, meso- and top predators (e.g., albatrosses, seals, penguins) are currently being considered as early ecological indicator species of changes in the Southern Ocean and are used as ecological indicators of the status of lower trophic levels (Hindell et al., 2003; Xavier and Cherel, 2009).

For benthic marine ecosystems, it is important to document and understand benthic functional diversity and to identify the ecological drivers of the different communities. Which environmental factors are responsible for the development of shelf-inhabiting filter-feeder dominated communities? Why are patches of such assemblages found in a gradient from aggregations restricted to a few meters to eco-regions extending to tens of kilometers? Furthermore, there is a need to investigate the dynamics of benthic systems, including seasonal variability, in order to map biodiversity, and biomass hot spots, as well as to elucidate turn-over rates between trophic levels and community-level nutrient cycles including consumption, carbon sequestration, and re-mineralization. Some of these challenges do relate to deep sea ecosystems (Brandt et al., 2007, 2012), in which our understanding of deep-sea organisms dynamics in a physically changing ocean, and under a varying climate,

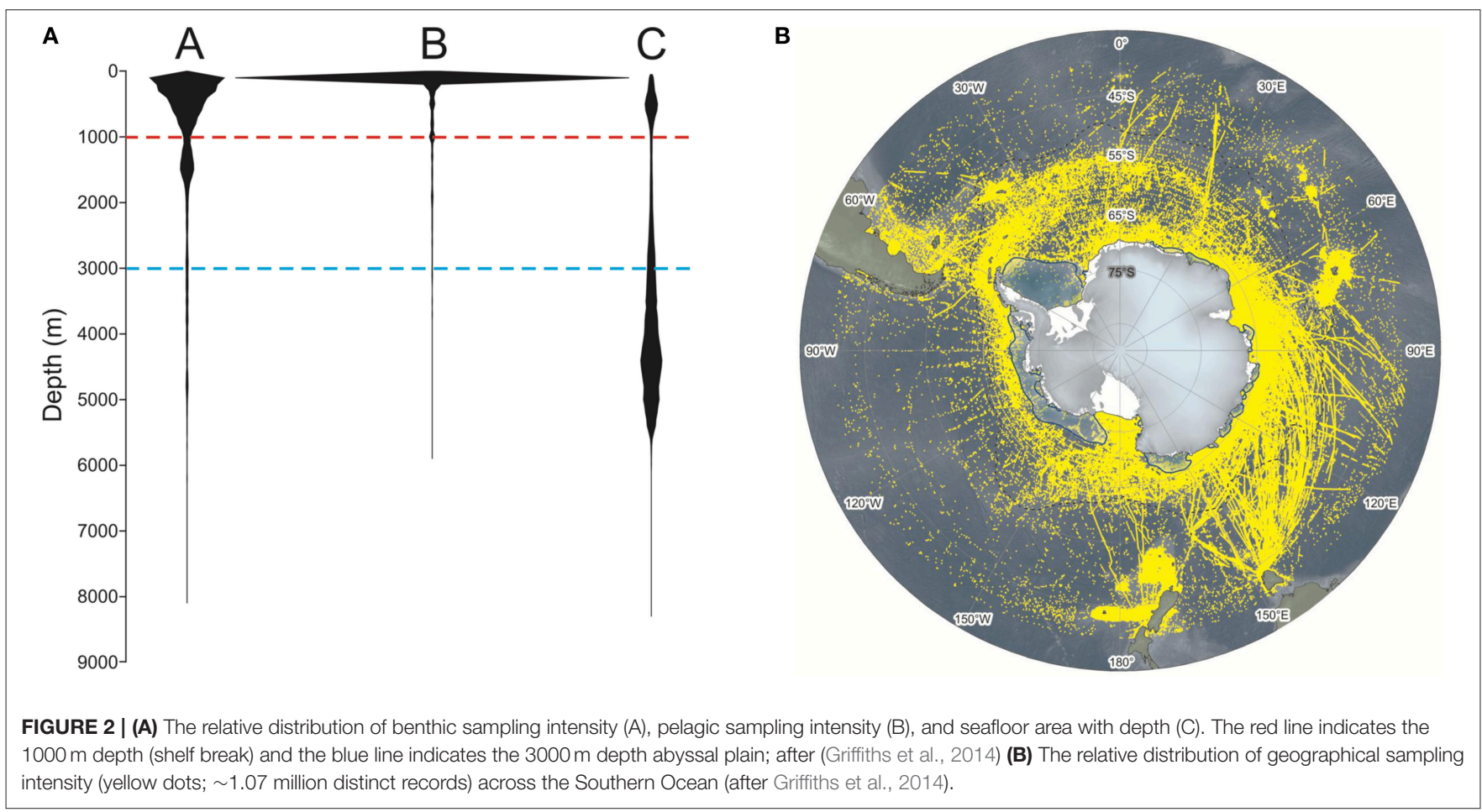


is key to evaluating the role of these organisms. The deep-sea, where ecological communities are diverse yet mostly unknown, represents one of the frontiers to explore in the coming decades as the basics of ecosystem functioning (Brandt and Ebbe, 2011) and changes in species functioning and food-web structure are almost unknown (Brandt et al., 2014a,b). The relatively stable Southern Ocean deep-sea ecosystems holds an enormous potential for evolutionary research, for example in determining the key factors that lead to speciation events in this vast environment. Moreover, it is important to understand the contribution to carbon and nutrient sequestration/recycling of the various plankton and benthic communities in the deep sea, on the slopes, and on/across the biomass-rich shelves.

Only when these gaps in knowledge are filled, the Antarctic marine systems can be described qualitatively and quantitatively and considered in a wider context that will allow predictions in a changing environment.

\section{FUTURE CHALLENGES AND REQUIREMENTS IN METHODOLOGICAL AND TECHNOLOGICAL DEVELOPMENTS \\ Future Requirements for Southern Ocean Life and Ecology Research}

Antarctic life sciences are constrained by the paucity of autoecological baseline data for key marine organisms (Kennicutt et al., 2014), particularly micro-organisms despite their fundamental importance in ecosystem functioning (Danovaro et al., 2014). There is vastly more data on species distribution compared to how they function and their productivity. Besides traditional - but often methodologically challenging - censuses, future generations of scientists will have to foster international coordination to conduct long-term monitoring programs and obtain biological information about poorly known species and their interactions, either directly, or through the use of ecological indicator species. These long-term, multi-national monitoring programs will also help to improve the quality and selection of data for the next generation of climate and food-web models. The accurate selection of essential Ecosystem Ocean Variables (Constable et al., 2014), for instance, is required to reliably predict regional or global Antarctic marine ecosystems (Murphy and Hofmann, 2013; Xavier et al., 2015).

Antarctic ecosystem services are increasingly important and there is an urgent need to clarify their role and the impacts of change. How does ecosystem functioning inform ecosystem services? How does it contribute to the global budget, and more specifically, to the Southern Ocean? Marine Protected Areas (MPAs), which have been implemented with varying success throughout the world's oceans, may play a crucial role in protecting Southern Ocean environments. Our ability to implement and then determine the efficiency and effectiveness of MPAs in protecting ocean resources is paramount in ensuring their sustainable exploitation and-will again-require longterm monitoring. For this, a better understanding of the structural and functional differences between the regions of the Southern Ocean is also crucial.
International organizations, such as the SCAR and the Commission for the Conservation of Antarctic Marine Living Resources (CCAMLR), gather expert scientific groups for whom monitoring is a key issue necessary to conduct academic research, promote species conservation, area protection, and ecosystem sustainability for Southern Ocean life. The recentlyestablished international initiative Southern Ocean Observing System (SOOS; www.soos.aq/) in alliance with the Global Ocean Observing System (www.ioc-goos.org/) and the Deep Ocean Observing Systems (www.ioc-goos.org/deepocean), aim at coordinating and expanding the efforts to collect scientific data in the Southern Ocean, and to develop a coherent and efficient observing system that will deliver the data required to address key scientific and societal challenges. Improved coordination of ecological process studies can be facilitated by international SCAR initiatives, such as the biology programs AnT-ERA (www.scar.org/srp/ant-era) and AntEco (www.scar.org/srp/anteco).

Under requirement and/or pressure from stakeholders to provide comprehensive knowledge of Southern Ocean ecosystems, it is essential to apply the often-invoked demand for standardization. This refers to sampling methods as well as analyses and strategies, even in simple parameters, such as absence/presence and abundance. The CCAMLR ecosystem monitoring program (CEMP) has put considerable effort into this issue, and has been collecting data on various species around the Southern Ocean since 1987 (Agnew, 1997). These efforts must be continued and expanded while encouraging research groups to use CEMP as a standard procedure for their data collection. Standardization and coordination, however, must not block the development of new technology and ideas, but rather complement these. In addition, efforts have to be made in order to obtain integrative results that are representative for entire communities or trophic components of the ecosystem.

Similarly, the challenges of conducting cutting-edge Antarctic marine science require a network of logistics and technologies to be developed, combining neural networks, data collection coordination, and a wide range of devices (Meredith et al., 2013). Future research vessels may have state-to-the-art instrumentation and laboratory facilities on board, together with next generation of non-invasive technologies (e.g., marine remotely operated vehicles, and autonomous underwater vehicles, gliders and rovers), as well as advanced Lander technology (i.e., any platform that carries one or more instruments to the seabed, remains there until it is recovered). Furthermore, autonomous profiling floats will continue to be extremely useful to collate valuable information and provide long-term trends in the future (Gille, 2002; Sallée et al., 2010; Tagliabue et al., 2014; Heuzé et al., 2015). Using such data, with those possible obtained from satellites (due to improved accuracy and uncertainty) will also aid our information about Ocean processes (Sarmiento et al., 1998; Arrigo et al., 1999; Arrigo, 2005; Hauck et al., 2015), ecology and food webs dynamics (Gillett and Thompson, 2003; Weimerskirch et al., 2012; Siegel et al., 2014; Laufkötter et al., 2015; Xavier et al., 2015). These technologies are efficient and environmentally friendly and will dramatically improve the spatial and temporal 
coverage of biological and physical sampling of the Southern Ocean. Moreover, they will help underpin how ecological observations should be collected, and assess Essential Ocean Variables (EOV's), that are in the focus of large international Antarctic programs, such as SOOS (Meredith et al., 2013, 2015).

Taxonomic descriptions of new species, providing the baseline knowledge on which all other research is built, has to be ensured, e.g., through support of taxonomists and the advancement of programs, such as Description language for Taxonomy (Dallwitz et al., 1993), combined with molecular methods. In parallel, technological progress and constant miniaturization have allowed animal data-recording or data-transmitting devices (Cooke et al., 2004; Ropert-Coudert and Wilson, 2005) to become increasingly useful in monitoring a wider range of parameters on smaller species without concern for adverse impacts. Forecasted miniaturization, concomitantly to the widening of the market for bio-logging technologies will result in the development of increasingly cheaper devices. This will open avenues for largescale monitoring operations at the circumpolar level in the coming decades. The development of new sensors and on-board data-processing systems augurs for future studies to determine in situ, and store, in enhanced memories, information about the environment at fine scales so as to provide a true dynamic vision of the state of the Southern Ocean. Linking the foraging behavior, trophic interactions and population dynamics of top predators, will also contribute significantly to the development of more efficient food-web models, which are crucial for the assessments of the life in the changing Southern Ocean. Universal food-web models (e.g., bringing together trophic interactions, biodiversity, biotic, and abiotic parameters, under evolutionary contexts), following previous research in this direction (Steinacher et al., 2010; Bopp et al., 2013), may be developed to explain the evolutionary origin of a high biodiversity in the Southern Ocean, their ecological coexistence and future response to ongoing environmental change. Finally, the continuous improvements for realizing cost-effective high-throughput molecular sequencing will also impact various disciplines, including biogeochemistry, following previous work (Bohmann et al., 2014; Zhan and MacIsaac, 2015).

\section{Develop Southern Ocean Marine Food Webs Forecasting Systems}

Modeling forecasting tools have been developed and available to allow predictions, although there is a need for improvement (Xavier et al., 2015). From a marine food webs forecasting perspective, in order to improve worldwide biological forecasting (i.e., predicting biological responses of organisms from local to global scales) (Barnosky et al., 2012), we need to be able to evaluate the ecological tipping points of Southern Ocean ecosystems (Gutt et al., 2013). Moreover, assessing how these tipping points may affect Southern Ocean functioning is a relevant issue for the coming 20 years. To this end, in addition to traditional monitoring, we need to conduct experimental manipulations over long timescales (e.g., several decades) on ecological indicator species (defined here as any biological species that defines a trait or characteristic of the environment) or groups of species.

It remains a challenge to incorporate life-history parameters (e.g., growth, mortality) within static species distribution models (Gutt et al., 2012) that correlate biogeography with recent and future environmental dynamic components. Furthermore, it is difficult to consider all ecologically relevant species, or the entire community, under multiple-instead of single-stressors in ecological risk models (Gutt et al., 2015). Special attention should be paid to invasive marine species or indigenous species that extend their biogeographic range and may cause a diversity shift that will disturb an existing dynamic equilibrium between trophic guilds.

One of the questions of interest to Antarctic marine resource managers and policy makers concerns with our ability to differentiate ecosystem changes and climate-driven change from the effects of fisheries exploitation (Figure 3). With respect to management of Southern Ocean living resources, in the face of near-future environmental change, CCAMLR endorsed the development of a feedback management strategy. This system will use information on the status of the ecosystem to alter the levels of harvesting and spatial management of the Antarctic krill fishery. Such an approach offers the opportunity to make the initial attempts to forecast, and respond accordingly to, the potential impacts of climate change (CCAMLR, 2014) through signals from components of the ecosystem such as meso- and top predators. Similar initiatives must be carried out for other currently commercially exploited species, such as toothfish and icefish, whilst knowledge gaps in the ecology of species that have the potential to be exploited in the future should urgently be identified. The possibility to use Antarctic top predators as oceanographic samplers has already been demonstrated. For example, Southern elephant seals Mirounga leonina habitat cover huge areas of the Southern Ocean and are therefore useful to examine physical and biological changes occurring in the vast, remote, Southern Ocean throughout the year (Roquet et al., 2013). Further developments in the use of top predators as oceanographic samplers, bearing ethical concerns in mind, would not only address key issues on the ecology of the species, but also be an important step toward a more complete sampling and monitoring of the Southern Ocean.

\section{Build Comparative Marine Research Programs between Polar Regions}

The Arctic and the Antarctic differ in age, stability and heterogeneity, human presence, and ecosystem services (Meltofte et al., 2013; Walton, 2013), yet various marine species occur at both poles (De Broyer et al., 2014). How polar ecosystems are responding and will respond to change is paramount to our understanding of worldwide processes, and therefore much insight can be gained from comparative studies (Smetacek and Nicol, 2005; Convey et al., 2012; Bennett et al., 2015). Comparing these Polar Regions at species- and ecosystem-functioning levels will be very important in the coming years, under climate change scenarios, through collaboration across the international 
scientific community (e.g., Under SCAR and the International Arctic Science Committee expert groups).

\section{Support an Ethical Perspective While Conducting Antarctic Science}

Southern Ocean ecosystems are remote, sometimes isolated and may, consequently, be more easily affected by changes. Signals of natural dispersal, colonization, and diversification for Antarctica and the Southern Ocean are now at risk of being overwhelmed by impacts associated with changing climates and rapidly increasing human movement both into the region and between its distinct regions (Chown et al., 2015). These characteristics imply that scientists must exert special care when conducting their experiments and, in this context, the international nature of Antarctic Science calls for a greater coordination among countries in defining ethical guidelines that will address the challenges of the coming decades. Based on the Protocol on Environmental Protection to the Antarctic Treaty (Madrid Protocol) national Antarctic programs should continue to submit their science proposals to the impartial, national environmental agencies, but procedures may differ for each country. This diversity in the evaluation processes means that the same survey or experiment submitted to two different countries may not experience the same level of restriction. In addition, ethics committees could be aware of specific scientific approaches (e.g., animal experiments with higher vertebrates entailed by working in the Southern Ocean) and make sure that their regulations still allow for data collection to take place. Absence of data could indeed be extremely prejudicial to producing effective conservation measures.

\section{Establish and Further Develop Education and Outreach More Efforts}

Due to the huge public interest in Antarctic animals (e.g., penguins, seals, whales) education and outreach efforts like those conducted during the Antarctic Treaty Consultative Meetings, by the Association of Polar Early Career Scientists and the Polar Educators International, as well by national programs,

\section{(3) ENVIRONMENTAL CHANGES (e.g. $T^{\circ}$, pH, 02, turbidity, nutrient load)}
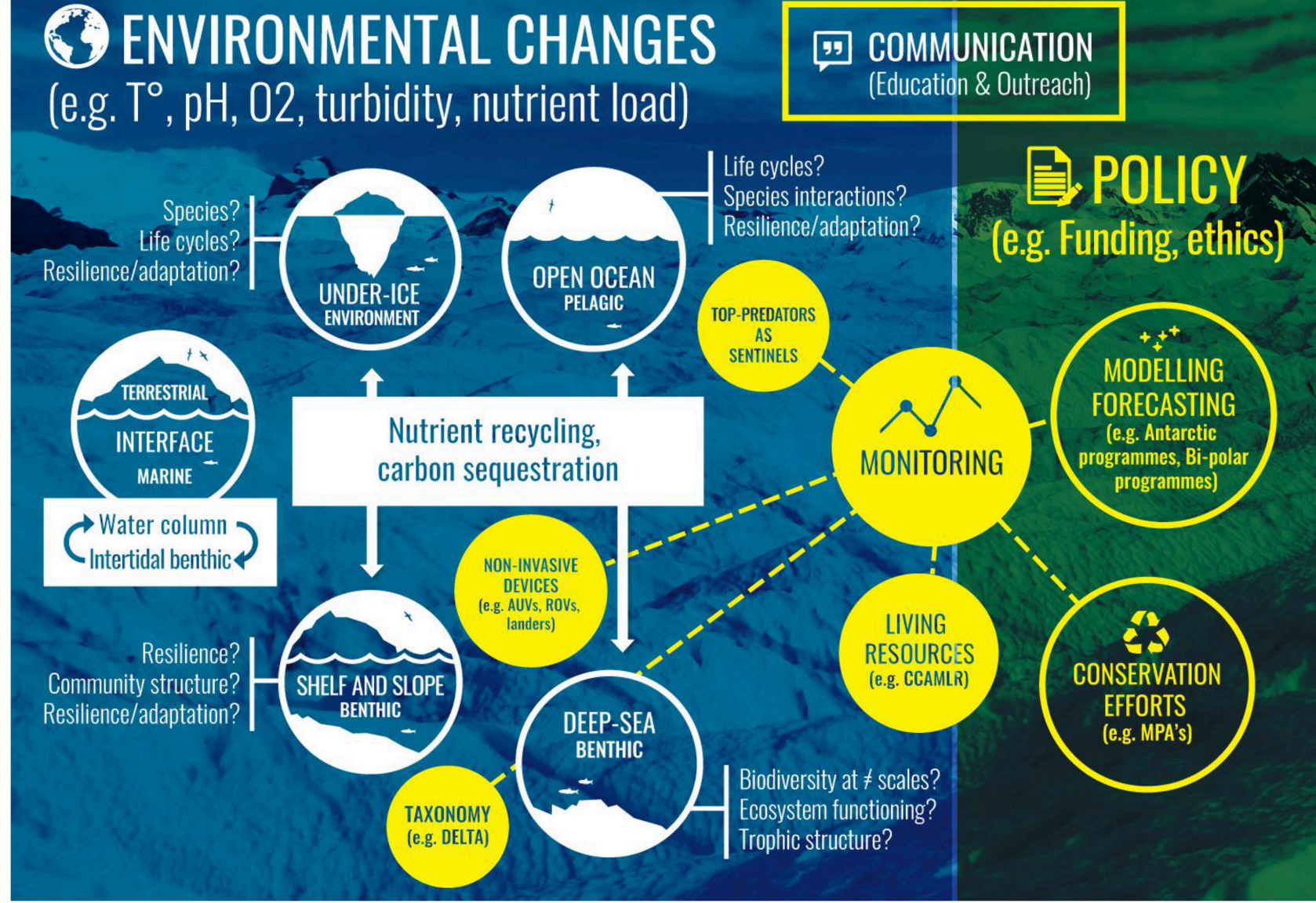

FIGURE 3 | Conceptual diagram illustrating gaps of knowledge in Southern Ocean life and ecology research, examples of the main needs for technological developments, and how these must be linked to monitoring and modeling efforts to forecast future changes in the Southern Ocean. The results of these research fields/gaps may have policy applications, such as on conservation efforts, concomitant with a strong communication (education and outreach) component. 
have raised Antarctic science profiles to a broader audience than the scientific and conservation communities currently reached (Baeseman et al., 2011; Walton et al., 2013; May et al., 2014). As such, Antarctic marine ecologists should be encouraged to engage in science communication to the general public, address societal concerns about Antarctic environmental issues (Pace et al., 2010; Xavier et al., 2016), and be actively involved in providing the best scientific information and advice to policy making bodies. If Antarctica-is to be protected, remote ecosystems like the Southern Ocean deep-sea, under-ice shelves and those under permanent sea-ice, will have to be studied and monitored more intensively than in the past and principles of modern conservation science must be applied (Kennicutt et al., 2014), and be promoted within society and in future research initiatives.

\section{CONCLUSIONS}

The first SCAR Antarctic and Southern Ocean Science Horizon Scan identified the most urgent science questions to be addressed within the next two decades. Based on the questions originally sent by the scientific community we consider the major gaps in the present ecological knowledge that are essential to shed light on tomorrow's Southern Ocean life and ecology. We concluded that basic biological information on the taxonomy (and the physiology) of organisms, ranging from viruses to top predators (particularly the former), is still lacking, as well as in areas such as the deep-ocean floor or the under-ice environments. At an ecosystem level, the response and resilience to change is largely unknown, rendering accurate forecasting virtually impossible in the near future. However, a future thorough understanding of these responses will be crucial for quantifying the importance of the various components of Antarctic ecosystem services (e.g., biodiversity and carbon sequestration), and the relative impact of future environmental change on these services. Filling in these gaps will require the continuation of a longterm commitment and the development and use of innovative technology to adequately research and monitor the Southern Ocean ecosystems, to detect changes at an early stage, and to evaluate multi-stressor effects in marine ecosystems in order to improve modeling efforts focused on interactive effects. Importantly, disciplines like taxonomy and long-term monitoring should receive strong logistical and financial support if we are to predict likely consequences of climate change and other threats. Finally, informing stakeholders, policy makers and the general public on the results of these studies will draw attention to the importance of this unique ecosystem, emphasize

\section{REFERENCES}

Agnew, D. J. (1997). Review the CCAMLR ecosystem monitoring programme. Antarctic Sci. 9, 235-242. doi: 10.1017/S095410209700031X

Arrigo, K. R. (2005). Marine microorganisms and global nutrient cycles. Nature 437, 349-355. doi: 10.1038/nature04159

Arrigo, K. R., Robinson, D. H., Worthen, D. L., Dunbar, R. B., DiTullio, G. R., VanWoert, M. et al. (1999). Phytoplankton community structure and the its global pivotal role, and most importantly, its increasing vulnerability to human-induced changes.

\section{AUTHOR CONTRIBUTIONS}

JX, AB, and YR coordinated the manuscript and all the authors contributed (writing and reviewing) the manuscript. All authors were highly active at the Horizon Scan, coordinating sessions with the Horizon Scan.

\section{ACKNOWLEDGMENTS}

We thank the organizers and all participants of the first SCAR Antarctic and Southern Ocean Science Horizon Scan and the Tinker Foundation for financial support, as well as Antarctica New Zealand, the New Zealand Antarctic Research Institute, the Scientific Committee on Antarctic Research, the Council of Managers of National Antarctic Programs, the Alfred-Wegner-Institut, Helmholtz Zentrum für Polar- und Meeresforschung (Germany), and the British Antarctic Survey. Support was provided by the Antarctic Climate \& Ecosystems Cooperative Research Centre (Australia), the Canadian Polar Commission, the Climate and Cryosphere Program, Kelly Tarlton's Sea Life Aquarium, the Korean Polar Research Institute, the Instituto Antarctico Chileno, the National Institute for Polar Research (Japan), New Zealand Post, the Programma Nazionale di Ricerche in Antartide (Italy), Monash University, Polar Research Institute of China, and the University of Malaya (Malaysia). The support of the SCAR Secretariat and Antarctica New Zealand staff is gratefully recognized. We thank Bruno Cruz, Huw Griffiths, Peter Bucktrout, Graham Hosie, Torben Riehl, and Lloyd Peck for preparing and contributing with figures/photos/comments to the manuscript. Finally, we also thank members of the SCAR expert groups (e.g., SCAR EGBAMM, Trophic interactions WG, ICED AG) and science research programs AnT-ERA and AntEco, for providing their valuable opinion. JX is supported by the Investigator FCT program (IF/00616/2013) and by the Foundation for Science and Technology (Portugal). WS is funded by Arcadia.

\section{SUPPLEMENTARY MATERIAL}

The Supplementary Material for this article can be found online at: http://journal.frontiersin.org/article/10.3389/fmars. 2016.00094 drawdown of nutrients and $\mathrm{CO}_{2}$ in the southern ocean. Science 283, 365-367. doi: $10.1126 /$ science.283.5400.365

Baeseman, J., Xavier, J. C., Lantuit, H., and Taylor, A. (2011). "Early career researcher activities during the 4th International Polar Year (IPY)," in Understanding Earth's Polar Challenges: International Polar Year 2007-2008, eds I. Krupnik, I. Allison, R. Bell, P. Culer, D. Hik, J. Lopez-Martinez, V. Rachold, E. Sarukhanian, and C. Summerhayes (Rovaniemi: University of the Arctic/CCI Press; Edmonton, AB: 
ICSU/WMO Joint Committee for International Polar Year 2007-2008). 511-522.

Barnosky, A. D., Hadly, E. A., Bascompte, J., Berlow, E. L., Brown, J. H., Fortelius, M., et al. (2012). Approaching a state shift in Earth's biosphere. Nature 486, 52-58. doi: $10.1038 /$ nature 11018

Bennett, J. R., Shaw, J. D., Terauds, A., Smol, J. P., Aerts, R., Bergstrom., D. M., et al. (2015). Polar lessons learned: long-term management based on shared threats in Arctic and Antarctic environments. Front. Ecol. Environ. 13:316. doi: $10.1890 / 140315$

Bohmann, K., Evans, A., Gilbert, M. T. P., Carvalho, G. R., Creer, S., Knapp, M. et al. (2014). Environmental DNA for wildlife biology and biodiversity monitoring. Trends Ecol. Evol. 29, 358-367. doi: 10.1016/j.tree.2014.04.003

Bopp, L., Resplandy, L., Orr, J. C., Doney, S. C., Dunne, J. P., Gehlen, M., et al. (2013). Multiple stressors of ocean ecosystems in the 21st century: projections with CMIP5 models. Biogeosciences 10, 6225-6245. doi: 10.5194/bg-106225-2013

Brandt, A., De Broyer, C., Ebbe, B., Ellingsen, K. E., Gooday, A. J., Janussen, D., et al. (2012). "Southern Ocean deep benthic biodiversity," in Antarctic Ecosystems: An Extreme Environment in a Changing World, eds A. D. Rogers, N. M. Johnston, E. J. Murphy, and A. Clarke (Oxford: Blackwell Publishing Ltd.), 291-334.

Brandt, A., and Ebbe, B. (2011). Southern Ocean biodiversity-from pelagic processes to deep-sea response. Deep Sea Res. II 19, 1945-2050. doi: 10.1016/j.dsr2.2011.05.003

Brandt, A., Gooday, A. J., Brix, S. B., Brökeland, W., Cedhagen, T., Choudhury, M., et al. (2007). The Southern Ocean deep sea: first insights into biodiversity and biogeography. Nature 447, 307-331. doi: 10.1038/nature05827

Brandt, A., Griffiths, H., Gutt, J., Linse, K., Schiaparelli, S., Ballerini, T., et al. (2014a). Challenges of Southern Ocean deep-sea biodiversity assessments. Adv. Polar Sci. 25, 204-212. doi: 10.13679/j.advps.2014.3.00204

Brandt, A., van de Putte, A. P., and Griffiths, H. (2014b). "Southern Ocean benthic deep-sea biodiversity and biogeography," in Biogeographic Atlas of the Southern Ocean, eds C. De Broyer, P. Koubbi, H. J. Griffiths, B. Raymond, C. d. Udekem d'Acoz, A. P. van de Putte, B. Danis, B. David, S. Grant, J. Gutt, C. Held, G. Hosie, F. Huettmann, A. Post, and Y. Ropert-Coudert (Cambridge, UK: Cambridge Scientific Committee on Antarctic Research).

CCAMLR (2014). Report of the Thirty-third meeting of the Commission. Commission for the Conservation of Antarctic Marine Living Resources, Hobart, Australia.

Chown, S. L., Clarke, A., Fraser, C. I., Cary, S. C., Moon, K. L., and McGeoch, M. A. (2015). The changing form of Antarctic biodiversity. Nature 522, 431-438. doi: $10.1038 /$ nature 14505

Constable, A. J., Melbourne-Thomas, J., Corney, S. P., Arrigo, K. R., Barbraud, C., Barnes, D. K., et al. (2014). Change in southern ocean ecosystems I: how changes in physical habitats directly affect marine biota. Glob. Chang. Biol. 20, 3004-3025. doi: 10.1111/gcb.12623

Convey, P., Aitken, S., di Prisco, G., Gill, M. J., Coulson, S. J., Barry, T., et al. (2012). The impacts of climate change on circumpolar biodiversity. Biodiversity 13, 134-143. doi: 10.1080/14888386.2012.732556

Cooke, S. J., Hinch, S. G., Wikelski, M., Andrews, R. D., Kuchel, L. J., Wolcott, T. G., et al. (2004). Biotelemetry: a mechanistic approach to ecology. Trends Ecol. Evol. 19, 334-343. doi: 10.1016/j.tree.2004.04.003

Costello, M. J., May, R. M., and Storck, N. E. (2013). Can we name EarthÕs species before they go extinct? Science 339, 413-416. doi: 10.1126/science.1230318

Dallwitz, M. J., Paine, T. A., and Zurcher, E. J. (1993). User's Guide to the DELTA System: A General System for Processing Taxonomic Descriptions, 4th Edn. Available online at: http://delta-intkey.com/www/uguide.htm

Danovaro, R., Snelgrove, P. V. R., and Tyler, P. (2014). Challenging the paradigms of deep-sea ecology. Trends Ecol. Evol. 29, 465-475. doi: 10.1016/j.tree.2014.06.002

De Broyer, C., Koubbi, P., Griffiths, H. J., Raymond, B., Udekem d'Acoz, Van de Putte, A. P., et al. (2014). Biogeographic Atlas of the Southern Ocean. Cambridge, UK: Scientific Committee on Antarctic Research.

Gille, S. T. (2002). Warming of the Southern Ocean since the 1950s. Science 295, 1275-1277. doi: 10.1126/science.1065863

Gillett, N. P., and Thompson, D. W. (2003). Simulation of recent southern hemisphere climate change. Science 302, 273-275. doi: 10.1126/science. 1087440
Golledge, N., Kowalewski, D., Naish, T., Levy, R., Fogwill, C., and Gasson, E. (2015). The multi-millennial Antarctic commitment to future sea-level rise. Nature 526, 421-425. doi: 10.1038/nature15706

Griffiths, H. J., Van de Putte, A. P., and Danis, B. (2014). "Data distribution: patterns and implications," in The CAML/SCAR-MarBIN Biogeographic Atlas of the Southern Ocean, eds C. De Broyer, P. Koubbi, H. J. Griffiths, B. Raymond, C. d. Udekem d'Acoz, A. P. Van de Putte, B. Danis, B. David, S. Grant, J. Gutt, C. Held, G. Hosie, F. Huettmann, A. Post, Y. and Ropert-Coudert (Cambridge: Scientific Committee on Antarctic Research), 16-26.

Gutt, J., Adams, B., Bracegirdle, T., Cowan, D., Cummings, V., di Prisco, G., et al. (2013). Antartic Thresholds - Ecosystem Resilience and Adaptation (AnT-ERA) a new SCAR-biology programme. Polarforschung 82, 147-150. doi: 10013/epic.43997

Gutt, J., Bertler, N., Bracegirdle, T. J., Buschmann, A., Comiso, J., Hosie, G., et al. (2015). The Southern Ocean ecosystem under multiple climate change stressesan integrated circumpolar assessment. Glob. Chang. Biol. 21, 1434-1453. doi: $10.1111 /$ gcb. 12794

Gutt, J., Hosie, G., and Stoddart, M. (2010). "Marine Life in the Antarctic," in Life in the World's Oceans: Diversity, Distribution, and Abundance, ed A. D. McIntyre (Oxford: Blackwell Publishing Ltd.), 203-220.

Gutt, J., Zurell, D., Bracegridle, T. J., Thomas, J., Cheung, W., Clark, M. S., et al. (2012). Correlative and dynamic species distribution modelling for ecological predictions in the Antarctic: a cross-disciplinary concept. Polar Res. 31:11091. doi: 10.3402/polar.v31i0.11091

Hauck, J., Völker, C., Wolf-Gladrow, D., Laufkötter, C., Vogt, M., Aumont, O., et al. (2015). On the southern ocean $\mathrm{CO}_{2}$ uptake and the role of the biological carbon pump in the 21st century. Global Biogeochem. Cycles 29, 1451-1470. doi: 10.1002/2015GB005140

Hernando, M. P., Schloss, I. R., Malanga, G., Almandoz, G. O., Ferreyra, G., Aguiar, M. B., et al. (2015). Effects of salinity changes on coastal Antarctic phytoplankton physiology and assemblage composition. J. Exp. Mar. Biol. Ecol. 466, 110-119. doi: 10.1016/j.jembe.2015.02.012

Heuzé, C., Vivier, F., Le Sommer, J., Molines, J. M., and Penduff, T. (2015). Can we map the interannual variability of the whole upper Southern Ocean with the current database of hydrographic observations? J. Geophys. Res. 120, 7960-7978. doi: 10.1002/2015jc011115

Hindell, M. A., Bradshaw, C. J. A., Sumner, M. D., Michael, K. J., and Burton, H. R. (2003). Dispersal of female southern elephant seals and their prey consumption during the austral summer: relevance to management and oceanographic zones. J. Appl. Ecol. 40, 703-715. doi: 10.1046/j.1365-2664.2003.0 0832.x

IPCC (2013). "Summary for policymakers," in Climate Change 2013: The Physical Science Basis Contribution of Working Group I to the Fifth Assessment Report of the Intergovernmental Panel on Climate Change, eds T. F. Stocker, D. Qin, G. K. Plattner, M. M. B. Tignor, S. K. Allen, J. Boschung, A. Nauels, Y. Xia, V. Bex, and P. M. Midgley (Cambridge, UK; New York, NY: Cambridge University Press), 1-27.

Kaiser, S., Brandão, S. N., Brix, S., Barnes, D. K. A., Bowden, D. A., Ingels, J., et al. (2013). Pattern, process and vulnerability of Southern Ocean benthos-a decadal leap in knowledge and understanding. Mar. Biol. 160, 2295-2317. doi: 10.1007/s00227-013-2232-6

Kennicutt, Chown, S. L., Cassano, J. J., Liggett, D., Massom, R., Peck, L. S., et al. (2014). Six priorities for Antarctic science (and suplementary information). Nature 512, 523-525. doi: 10.1038/512023a

Kennicutt, Chown, S. L., Cassano, J. J., Liggett, D., Peck, L. S., Massom, R., et al. (2015). A roadmap for Antarctic and Southern Ocean science for the next two decades and beyond. Antarctic Sci. 27, 3-18. doi: 10.1017/S0954102014000674

Laufkötter, C., Vogt, M., Gruber, N., Aita-Noguchi, M., Aumont, O., Bopp, L., et al. (2015). Drivers and uncertainties of future global marine primary production in marine ecosystem models. Biogeosciences 12, 6955-6984. doi: 10.5194/bg-126955-2015

May, I., Huffman, L. T., Xavier, J. C., and Walton, D. W. H. (2014). Education and polar research: bringing polar science into the classroom. J. Geol. Res. Eng. 4, 217-221. doi: 10.17265/2328-2193/2014.04.004

Meltofte, H., Barry, T., Berteaux, D., Bültmann, H., Christiansen, J.S., Cook, J.A. (2013). Arctic Biodiversity Assesment: Synthesis. Akureyri: Conservation of Arctic Flora and Fauna (CAFF). 
Meredith, M. P., Mazloff, M., Sallée, J.-B., Newman, L., Wåhlin, A., Williams, M. J. M., et al. (2015). Southern Ocean. Bull. Am. Meteorol. Soc. 96, S157-S160.

Meredith, M. P., Schofield, O., Newman, L., Urban, E., and Sparrow, M. (2013). The vision for a southern ocean observing system. Curr. Opin. Environ. Sustain. 5, 306-313. doi: 10.1016/j.cosust.2013.03.002

Murphy, E. J., and Hofmann, E. E. (2013). End-to-end in southern ocean ecosystems. Curr. Opin. Environ. Sustain. doi: 10.1016/j.cosust.2012.05.005

Orr, J. C., Fabry, V. J., Aumont, O., Bopp, L., Doney, S. C., Feely, R. A., et al. (2005). Anthropogenic ocean acidification over the twenty-first century and its impact on calcifying organisms. Nature 437, 681-686. doi: 10.1038/nature04095

Pace, M. L., Hampton, S. E., Limburg, K. E., Bennett, E. M., Cook, E. M., Davis, A. E., et al. (2010). Communicating with the public: opportunities and rewards for individual ecologists. Front. Ecol. Environ. 8:168. doi: 10.1890/090168

Pasotti, F., Manini, E., Giovannelli, D., Wölfl, A. C., Monien, D., Verleyen, E., et al. (2015). Antarctic shallow water benthos in an area of recent rapid glacier retreat. Mar. Ecol. 36, 716-733. doi: 10.1111/maec.12179

Rockstrom, J., Steffen, W., Noone, K., Persson, A., Chapin, F. S., Lambin, E. F., et al. (2009). A safe operating space for humanity. Nature 461, 472-475. doi: $10.1038 / 461472 \mathrm{a}$

Ropert-Coudert, Y., Kato, A., Meyer, X., PellŽ, M., MacIntosh, A. J. J., Angelier, F., et al. (2014). A complete breeding failure in an AdŽlie penguin clony correlates with unusual and extreme environmental events. Ecography 37, 1-3. doi: 10.1111 /ecog.01182

Ropert-Coudert, Y., and Wilson, R. P. (2005). Trends and perspectives in animalattached remote sensing. Front. Ecol. Environ. 3:437. doi: 10.1890/15409295(2005)003[0437:TAPIAR]2.0.CO;2

Roquet, F., Wunsch, C., Forget, G., Heimbach, P., Guinet, C., Reverdin, G., et al. (2013). Estimates of the Southern Ocean general circulation improved by animal-borne instruments. Geophys. Res. Lett. 40, 6176-6180. doi: $10.1002 / 2013 \mathrm{gl} 058304$

Sallée, J.-B., Speer, K. G., and Rintoul, S. R. (2010). Zonally asymmetric response of the Southern Ocean mixed-layer depth to the Southern Annular Mode. Nat. Geosci. 3, 273-279. doi: 10.1038/ngeo812

Sarmiento, J., Hughes, T., Stouffer, R., and Manabe, S. (1998). Ocean carbon cycle response to future greenhouse warming. Nature 393, 245-249. doi: $10.1038 / 30455$

Sarmiento, J. L., Gruber, N., Brzezinski, M. A., and Dunne, J. P. (2004). High-latitude controls of thermocline nutrients and low latitude biological productivity. Nature 427, 56-60. doi: 10.1038/nature02127

Schloss, I. R., Abele, D., Ferreyra, G. A., González, O., Moreau, S., Demers, S., et al. (2012). Response of Potter Cove phytoplankton dynamics to long term climate trends. J. Mar. Syst. 92, 53-66. doi: 10.1016/j.jmarsys.2011.10.006

Siegel, D. A., Buesseler, K. O., Doney, S. C., Sailley, S. F., Behrenfeld, M. J., and Boyd, P. W. (2014). Global assessment of ocean carbon export by combining satellite observations and food-web models. Global Biogeochem. Cycles 28, 181-196. doi: 10.1002/2013GB004743

Smetacek, V., and Nicol, S. (2005). Polar ocean ecosystems in a changing world. Nature 437, 362-368. doi: 10.1038/nature04161

Steffen, W., Richardson, K., Rockstršm, J., Cornell, S. E., Fetzer, I., Bennett, E. M., et al. (2015). Planetary boundaries: guiding human development on a changing planet. Science 347:1259855. doi: 10.1126/science.1259855

Steinacher, M., Joos, F., Frolicher, T., Bopp, L., Cadule, P., Cocco, V., et al. (2010). Projected 21st century decrease in marine productivity: a multi-model analysis. Biogeosciences 7, 979-1005. doi: 10.5194/bg-7-979-2010
Suckling, C. C., Clark, M. S., Beveridge, C., Brunner, L., Hughes, A. D., Harper, E. M., et al. (2014). Experimental influence of $\mathrm{pH}$ on the early life-stages of sea urchins II: increasing parental exposure times gives rise to different responses. Invert. Reprod. Dev. 58, 161-175. doi: 10.1080/07924259.2013. 875951

Sutherland, W. J., Fleishman, E., Mascia, M. B., Pretty, P., and Rudd, M. A. (2011). Methods for collaboratively identifying research priorities and emerging issues in science and policy. Methods Ecol. Evol. 2, 238-247. doi: 10.1111/j.2041210X.2010.00083. $x$

Tagliabue, A., Sallée, J.-B., Bowie, A. R., Lévy, M., Swart, S., and Boyd, P. W. (2014). Surface-water iron supplies in the Southern Ocean sustained by deep winter mixing. Nat. Geosci. 7, 314-320. doi: 10.1038/ngeo2101

Turner, J., Barrand, N. E., Bindschadler, R., Convey, P., Hodgson, D. A., Jarvis, M., et al. (2009). Antarctic Climate Change and the Environment. Cambridge, UK: Scientific Committee for Antarctic Research.

Walton, D. (2013). Antarctica: Global Science from a Frozen Continent. Cambridge, UK: Cambridge University Press.

Walton, D., Xavier, J. C., May, I., and Huffman, L. (2013). Polar Educators International - a new initiative for schools. Antarct. Sci 25, 473. doi: 10.1017/S0954102013000485

Weimerskirch, H., Louzao, M., De Grissac, S., and Delord, K. (2012). Changes in wind pattern alter albatross distribution and life-history traits. Science 335, 211-214. doi: $10.1126 /$ science. 1210270

Xavier, J. C., and Cherel, Y. (2009). Cephalopod Beak Guide for the Southern Ocean. British Antarctic Survey.

Xavier, J. C., Hill, S. L., Belchier, M., Bracegirdle, T. J., Murphy, E. J., and Lopes-Dias, J. (2015). "From ice to penguins: the role of mathematics in Antarctic research," in Mathematics of Energy and Climate Change. CIM Series in Mathematical Sciences, Vol. 2, eds J. P. Bourguignon, R. Jeltsch, A. A. Pinto, and M. Viana (Zürich: Springer-Verlag), 389-414.

Xavier, J. C., Fugmann, G., Beck, I., Huffman, L., and Jensen, E. (2016). "Education on biodiversity of the Polar Regions," in Biodiversity and Education for Sustainable Development (ESD), World Sustainability in the Series: Umweltbildung, Umweltkommunikation und Nachhaltigkeit - Environmental Education, Communication and Sustainability, eds P. Castro, U. M. Azeiteiro, P. Bacelar-Nicolau, W. Leal Filho, and A. M. Azul (Frankfurt: Peter Lang GmbH International Academic Publishers), 43-56. doi: 10.1007/978-3-31932318-3

Zhan, A., and MacIsaac, H. J. (2015). Rare biosphere exploration using highthroughput sequencing: research progress and perspectives. Conserv. Genet. 16, 513-522. doi: 10.1007/s10592-014-0678-9

Conflict of Interest Statement: The authors declare that the research was conducted in the absence of any commercial or financial relationships that could be construed as a potential conflict of interest.

Copyright (c) 2016 Xavier, Brandt, Ropert-Coudert, Badhe, Gutt, Havermans, Jones, Costa, Lochte, Schloss, Kennicutt and Sutherland. This is an open-access article distributed under the terms of the Creative Commons Attribution License (CC $B Y)$. The use, distribution or reproduction in other forums is permitted, provided the original author(s) or licensor are credited and that the original publication in this journal is cited, in accordance with accepted academic practice. No use, distribution or reproduction is permitted which does not comply with these terms. 